\title{
ESTRATIGRAFIA DO GRUPO BAMBUÍ NA SERRA DO JAÍBA, NORTE DE MINAS GERAIS.
}

\author{
Mario Iglesias ${ }^{1} \&$ Alexandre Uhlein ${ }^{2}$
}

\begin{abstract}
STRATIGRAPHY OF THE BAMBUÍ GROUP IN SERRA DO JAÍBA RANGE, NORTHERN MINAS GERAIS STATE. Serra do Jaíba is a small mountain range sited on the right side of the Verde Grande river (northern Minas Gerais state). The stratigraphy of this morfological feature is made up by siltstones, limestones and arkoses of the Bambuí Group (Neoproterozoic). The sedimentary succession of the Serra do Jaíba shows upper stratigraphic levels in comparison with other neighboring ranges at the same elevation. The presence of strata with opposite dips on both sides of the range represents a possible synclinal structure. This synclinal could explain the special stratigraphic arrangement of the Serra do Jaíba.
\end{abstract}

Key words: Serra do Jaíba, Bambui Group, stratigraphy, synclinal

\section{INTRODUÇ̃̃O}

A Serra do Jaíba, localizada ao longo da margem direita do Rio Verde Grande, constitui uma feição morfológica alinhada, por mais de $35 \mathrm{~km}$, segundo uma direção NE-SW, elevando-se mais de 200 metros sobre a planície aluvial do Rio Verde Grande, situado a oeste. A Serra do Jaíba localiza-se próximo às cidades de Janaúba e Verdelândia, no norte do Estado de Minas Gerais (Fig. 1 e 2).

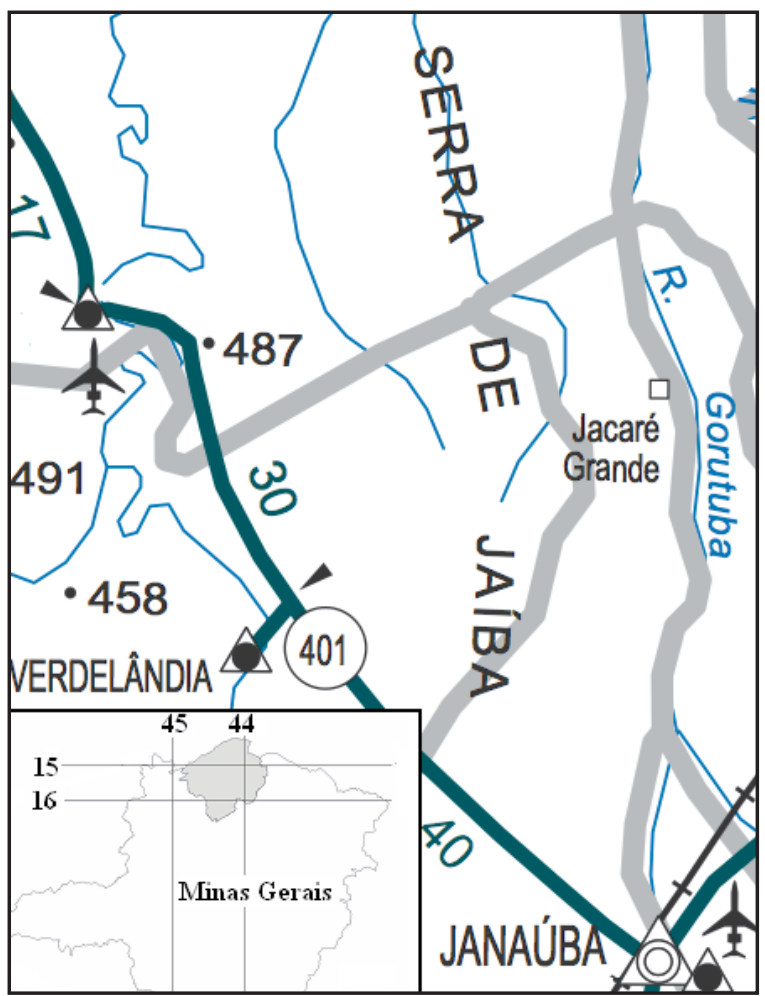

Figura1. Localização geral da Serra do Jaíba e, à direita, mapa rodoviário da zona de estudo.

Departamento de Estradas e Rodagem-DER (2004).
A estratigrafia da serra tem constituído motivo de discussão para diversos autores (Costa, 1978, Chiavegatto et al., 2003) que sugeriram diversas hipóteses sobre a sua disposição estratigráfica (falhamento regional, resposta sedimentar a eventos brasilianos, etc.) O presente trabalho traz uma proposta para a estratigrafia da região da Serra do Jaíba, tendo como base o acervo de dados estruturais e estratigráficos coletados nas pesquisas realizadas para a dissertação de mestrado de Iglesias (2007).

O tabuleiro do Rio Verde Grande representa uma imensa área peneplanizada, onde afloram coberturas detríticas aluvionares, eluvionares e coluvionares, que recobrem os afloramentos das rochas pelito-carbonáticas do Grupo Bambuí. Assim, a Serra do Jaíba constitui-se numa das escassas possibilidades que oferece a área para o estudo das litofácies do Grupo Bambuí em superfície. A serra permite ainda um detalhamento da coluna estratigráfica regional, daí a importância do seu conhecimento.

\section{ASPECTOS ESTRATIGRÁFICOS}

As litofácies que afloram na subida da Serra do Jaíba estão representadas na coluna estratigráfica da Figura 3.

A Serra do Jaíba exibe uma sucessão sedimentar constituída, da base para o topo, por siltitos argilosos de cor cinza esverdeada (Figura 4-A, 4-B), às vezes amarelados quando intemperizados, relacionados à Formação Serra da Saudade, apresentando cerca de 100 a 130 metros de espessura.

Sobrepondo-se aos pelitos, ocorre um pacote de cerca de $30 \mathrm{~m}$ de espessura, de rocha carbonática de cor cinza, intensamente laminada, composta por alternâncias de lâminas de calcilutitos de cor cinza e lâminas pelíticas (Figura 5-A e 5-B). 


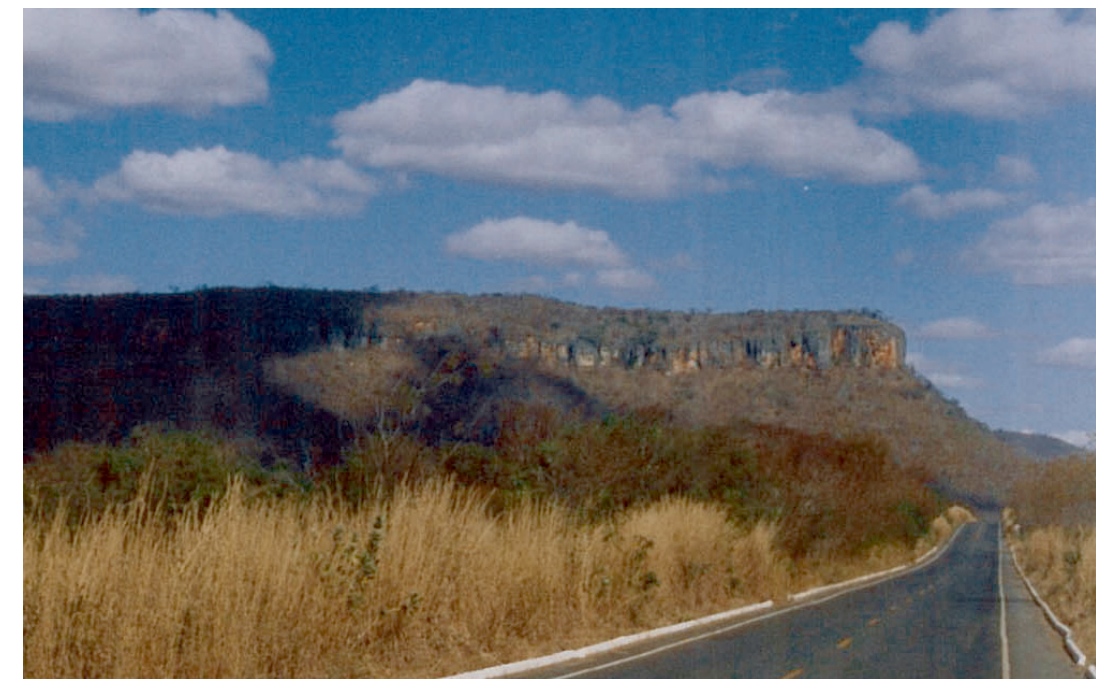

Figura 2- Vista da Serra do Jaíba, visando para SSE.

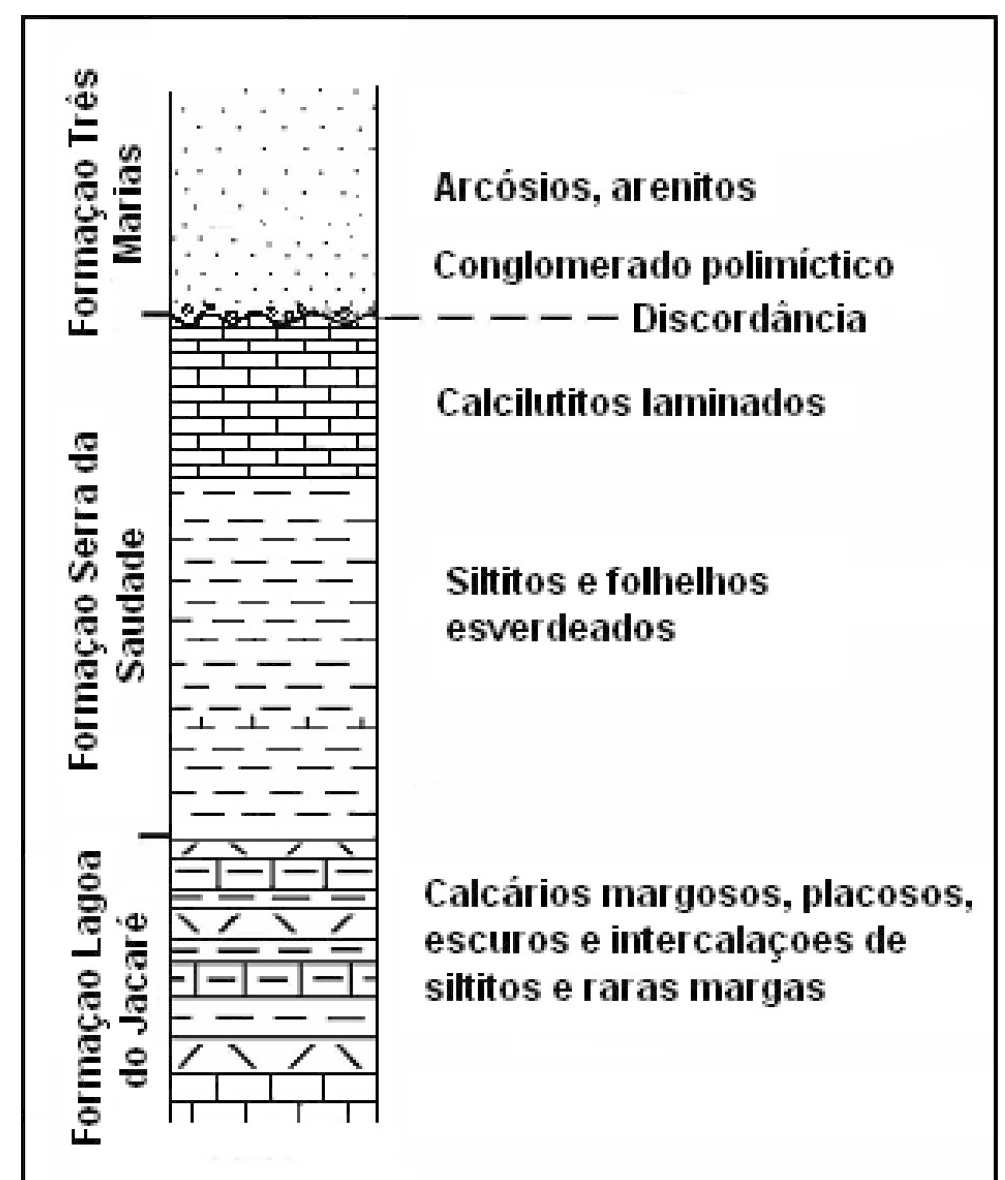

Figura 3- Coluna estratigráfica esquemática da região da Serra do Jaíba. Espessura aproximada $300 \mathrm{~m}$. (Modificado de Iglesias, 2007 e Iglesias \& Uhlein, no prelo).

Esta litofácies fica ressaltada no campo por constituir paredão abrupto, vertical ao longo de toda a serra (vide figura 2). Chiavegatto et al. (2003) interpretaram este calcário como sendo um laminito algal. Além disto, sugerem que esta rocha represente uma nova unidade estratigráfica dentro do Grupo Bambuí e a designaram como Formação Jaíba. Petrográficamente, observa-se que essa litofácies é composta pela alternância de lâminas silto-argilosas, terrígenas e de calcilutitos, sugerindo tratar-se de uma litofácies mixta, de granulometria muito fina, não mostrando nenhuma evidência de atividade microbiana.

Sobre o pacote carbonático repousa, em contato discordante e erosivo, um delgado nível $(0,5 \mathrm{~m})$ de conglomerados polimíticos, de matriz arcosiana e clastos de calcários, localmente também de siltitos, que representa a base da Formação Três Marias na Serra do Jaíba. Esta formação se constitui 

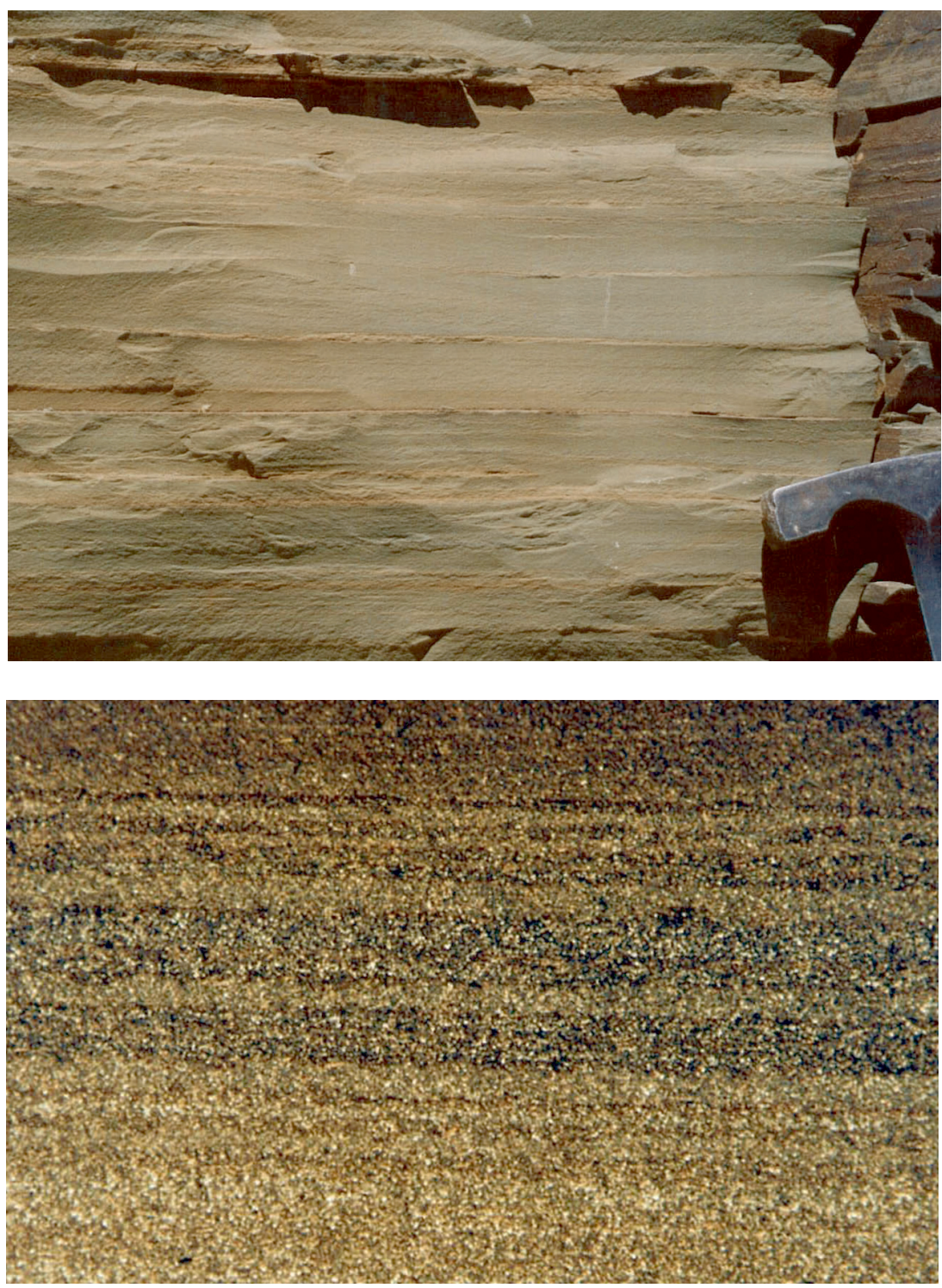

Figura 4-A) Siltitos da Formação Serra da Saudade em afloramentos na base da Serra do Jaiba (estrada MG-401, proximidades de Verdelândia). B) Fotomicrografia dos siltitos da Formação Serra da Saudade, mesmo local. As lâminas claras apresentam uma granulometría maior e composição quartzosa, as lâminas escuras são de composição predominantemente sericítica.

predominantemente de arcóseos, cinza esverdeados, calcíferos e apresenta uma grande variabilidade na espessura (de 50 a mais de $100 \mathrm{~m}$ ).

Os arenitos arcosianos (figura 6) são de granulometria grossa a média e mostram estratificações cruzadas acanaladas de pequeno a médio porte. As litofácies descritas para a Formação Três Marias indicam sedimentação fluvial. São semelhantes às litofácies identificadas no núcleo do sinclinal de Buenópolis (Uhlein, 1991; Uhlein et al., 2004). Estas litofácies, conglomerado e arenito conglomerático de ambiente fluvial podem indicar uma importante discordância de borda de bacia na evolução do Grupo Bambuí.

Os perfis litológicos dos poços tubulares realizados pela COPASA-MG, na área da planície do Rio Verde Grande, indicam que, estratigraficamente abaixo dos pelitos da escarpa da serra, em cota inferior a
$450 \mathrm{~m}$, existe um espesso pacote pelito-carbonático que pode ser associado à Formação Lagoa do Jacaré. Da mesma forma, observações na margem esquerda do Rio Verde Grande, situada a oeste, indicam afloramentos de calcarenitos pertencentes a mesma formação. Estas observações indicam que as litofácies de siltitos argilosos aflorantes na base da Serra do Jaíba pertencem à Formação Serra da Saudade.

\section{ASPECTOS ESTRUTURAIS}

A sucessão estratigráfica da Serra do Jaíba mostra pelitos da Formação Serra da Saudade sotopostos em discordância aos arenitos arcosianos da Formaçao Três Marias. Este seqüenciamento estratigráfico contrasta com as serras vizinhas (São Felipe e Serra Azul), onde, para a mesma cota topográfica, as serras próximas apresentam um nível estratigráfico inferior (Formação 


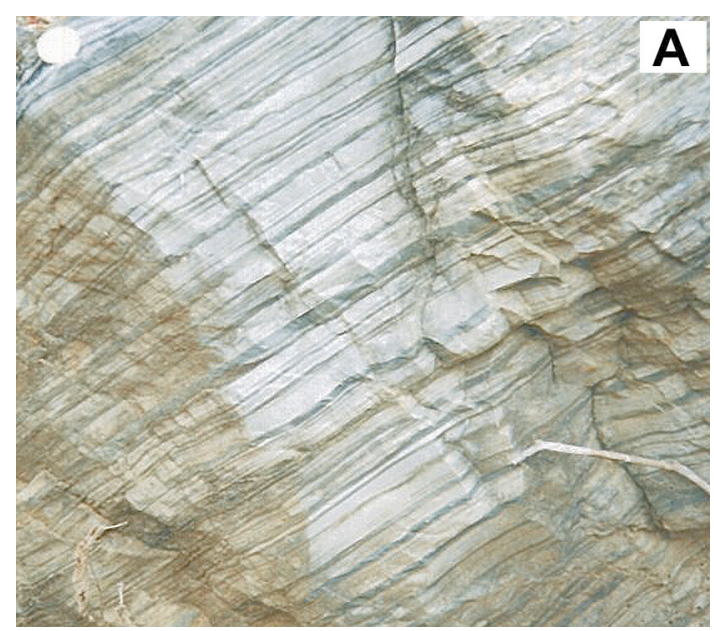

Grande, que pudesse sustentar essa hipótese.

Perfis regionais na área da Serra do Jaíba evidenciaram mergulhos opostos em ambos os flancos da serra. As medidas indicaram direções de mergulho de $100 / 15^{\circ}$ no flanco ocidental e $300 / 20^{\circ}$, em média, no flanco oriental. Isto indica uma estrutura sinclinal, com eixo NE-SW (paralelo à serra), resultado dos esforços tectônicos relacionados ao Ciclo Brasiliano, que foram responsáveis pela estruturação da faixa de dobramento Araçuaí, unidade geotectônica situada a cerca de $30 \mathrm{kms}$ para leste, em relação a área de pesquisa.

Na parte oeste da figura 7 observa-se um grande predomínio de camadas subhorizontais ou mostrando um suave mergulho de $5^{\circ}$ a $10^{\circ}$ para leste. Progressivamente, o mergulho para leste aumenta, assim como surge uma

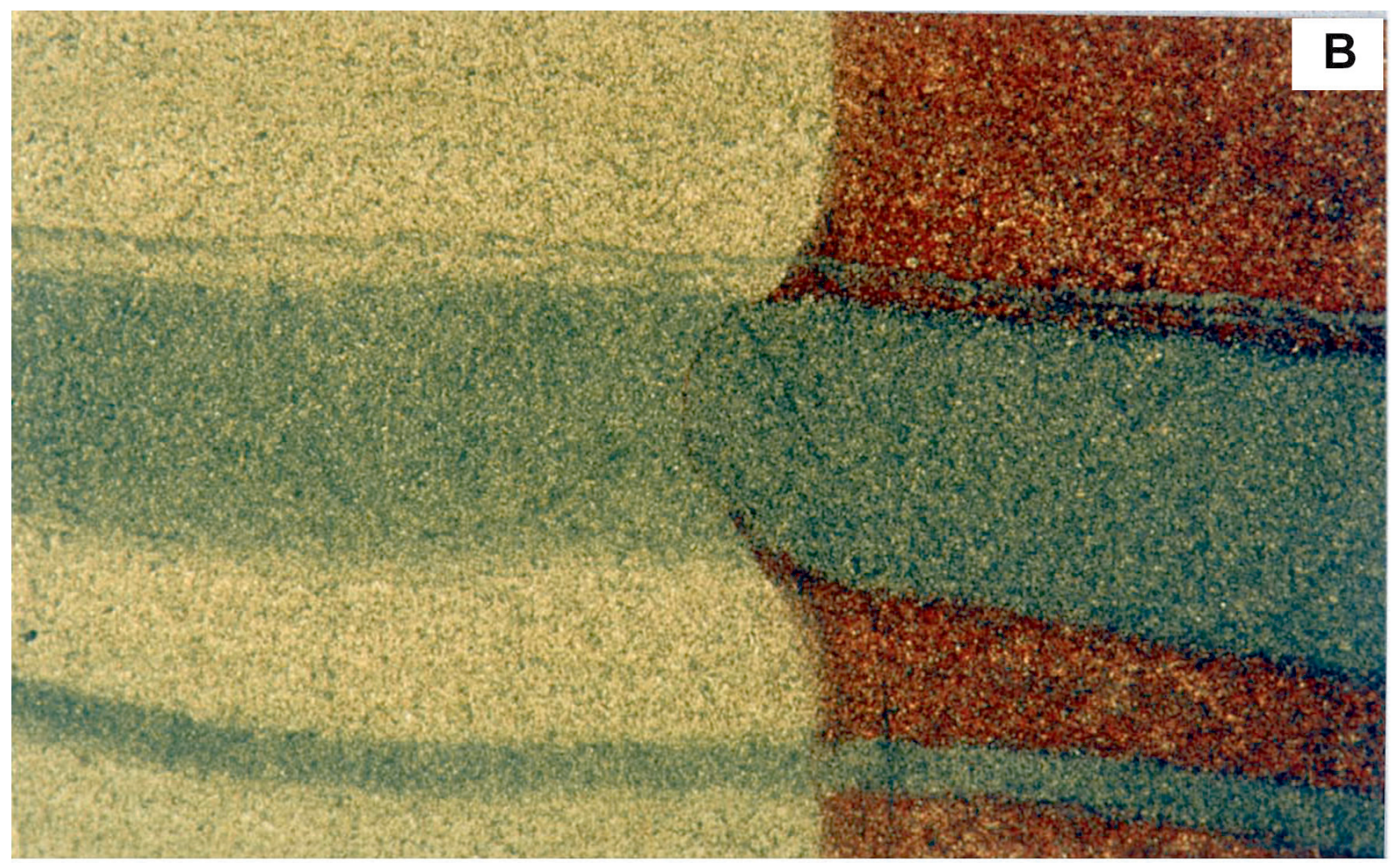

Figura 5-A: Afloramento de calcário laminado com delgadas intercalações de terrigenos (a escala está representada por uma moeda no canto superior esquerdo da foto). B) Fotomicrografia mostrando a alternância de laminas carbonáticas e pelíticas. As lâminas claras (escuras quando tingidas por Alizarina red-S) representam os níveis calcíticos e as lâminas cinza representam os níveis pelíticos, ricos em minerais micáceos.

Lagoa do Jacaré). Assim, na Serra de São Felipe (40 kms a leste de Jaíba), aflora a Formação Lagoa do Jacaré na cota $700 \mathrm{~m}$, enquanto que para essa mesma altitude, na Serra do Jaíba, encontramos a Formação Três Marias, topo do Grupo Bambuí. Uma estrutura do tipo sinclinal poderia explicar mais facilmente a preservação das litofácies de topo do Grupo Bambuí na Serra do Jaíba (figura 7).

Costa (1978) sugeriu a hipótese do rebaixamento por falhamento de um grande bloco (margem direita do Rio São Francisco), coincidente com a planície do Rio Verde Grande, o qual explicaria a configuração estratigráfica da área. Cabe ressaltar, no entanto, a impossibilidade de demonstrar qualquer evidência importante de falhamento ao longo do Rio Verde incipiente clivagem ardosiana. Nas proximidades de São João da Ponte e Verdelândia começam a aparecer dobramentos abertos e clivagem nítida plano-axial.

Estes dobramentos com clivagem plano-axial representam, também, manifestações do tectonismo brasiliano como influência da Faixa Araçuaí sobre o Grupo Bambuí. Dessa maneira, parte das rochas pelito-carbonáticas da Formação Lagoa do Jacaré e pelíticas da Formação Serra da Saudade apresentam uma foliação incipiente com atitude média de $120 / 55^{\circ}$ (Figura 8-A). Os calcários da porção média da Serra do Jaíba apresentam dobramentos assimétricos importantes (Figura 8-B), indicando os esforços compressivos relacionados ao ciclo Brasiliano.

Foi realizado um estudo estatístico de medidas 

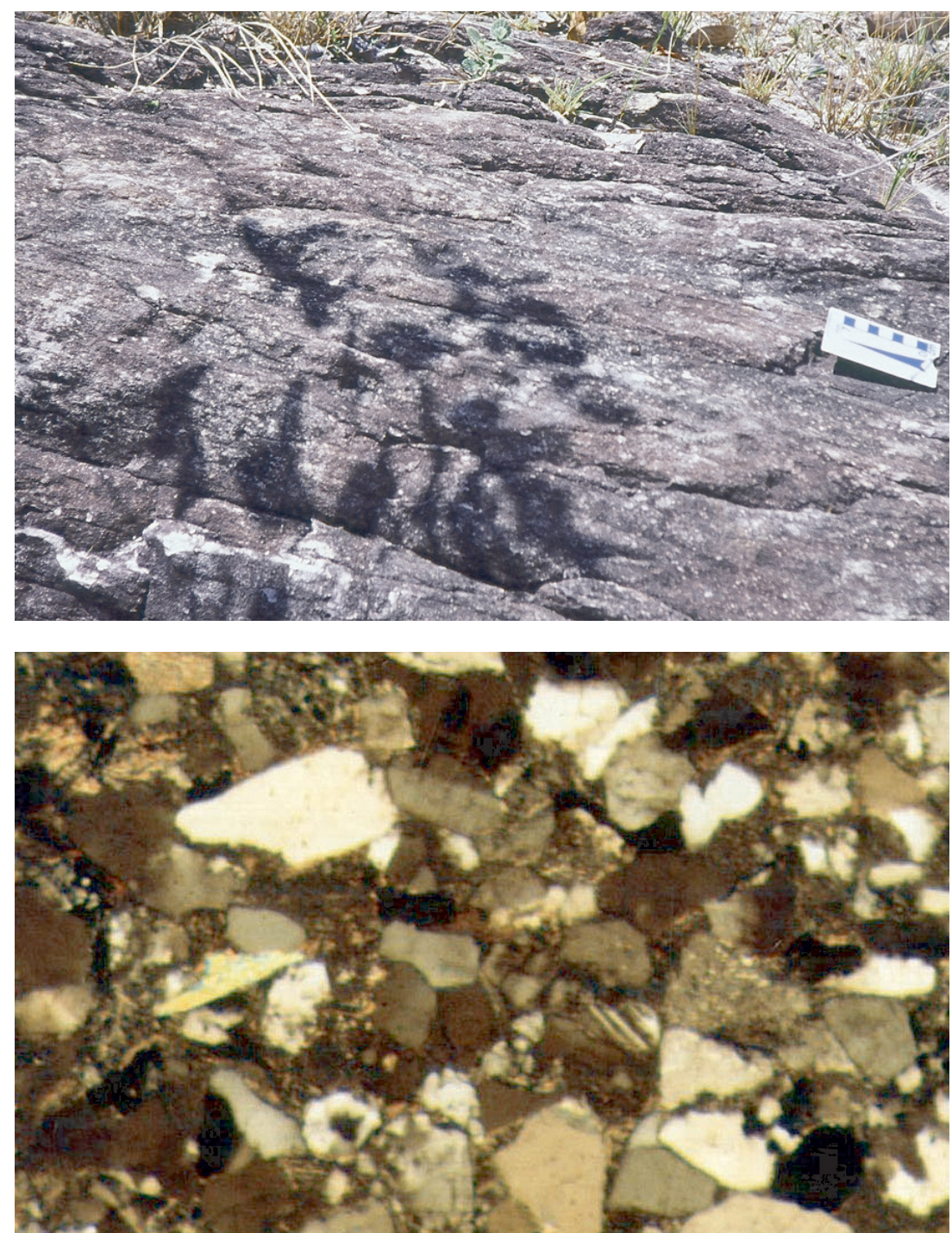

Figura 6-A) Lajedo de arcóseos no topo da Serra do Jaiba. Podem ser observados alguns planos oblíquos pertencentes a estratificações cruzadas. B) Fotomicrografia dos arenitos arcosianos da Formação Três Marias, mostrando abundância de grãos angulosos de quartzo e feldspatos.

da orientação de fraturas nas rochas dos afloramentos mais expressivos da região (Iglesias, 2007). A partir da análise e medidas estatísticas das fraturas em afloramentos e do estudo de fotolineamentos em imagens de satélite foram estabelecidos os principais lineamentos, definindo-se assim quatro (04) sistemas principais de fraturamento, segundo as direções: NE, EW, NW e NS (Figura 9). Estes lineamentos representam, da mesma forma, a compressão Brasiliana relacionada a estruturação regional. Silva (1984) utilizando análise morfo-estrutural, interpretou esses lineamentos como fraturamentos decorrentes de esforços de compressão do Ciclo Brasiliano.

\section{CONCLUSÕES}

A partir dos dados acima expostos, pode-se concluir que a estratigrafia da Serra do Jaíba é composta, da base para o topo, pelos siltitos da Formação Serra da Saudade, com espessura em torno de 100 metros. Para o topo ocorre um pacote carbonático de pequena espessura e de origem discutida, o qual pode ser pertencente à Formação Serra da Saudade. Ambas as litofácies representam sedimentação marinha. No topo da Serra do Jaíba afloram arcóseos com estratificações cruzadas e um conglomerado basal descontínuo, pertencentes à Formação Três Marias. Os arcóseos constituem litofácies de origem fluvial, indicando uma discordância de borda de bacia.

A sucessão sedimentar da Serra do Jaíba, representada pelas unidades superiores do Grupo Bambuí, contrasta com a estratigrafia encontrada, para a mesma cota, nas serras próximas. A evidência de mergulhos opostos em ambos os flancos da serra indica uma estrutura sinclinal, de eixo NNE-SSW. Na Serra do Jaíba observam-se ainda numerosos fraturamentos, dobras e foliação incipiente, todos eles resultantes dos esforços do Ciclo Brasiliano, que originaram à Faixa Araçuaí. 


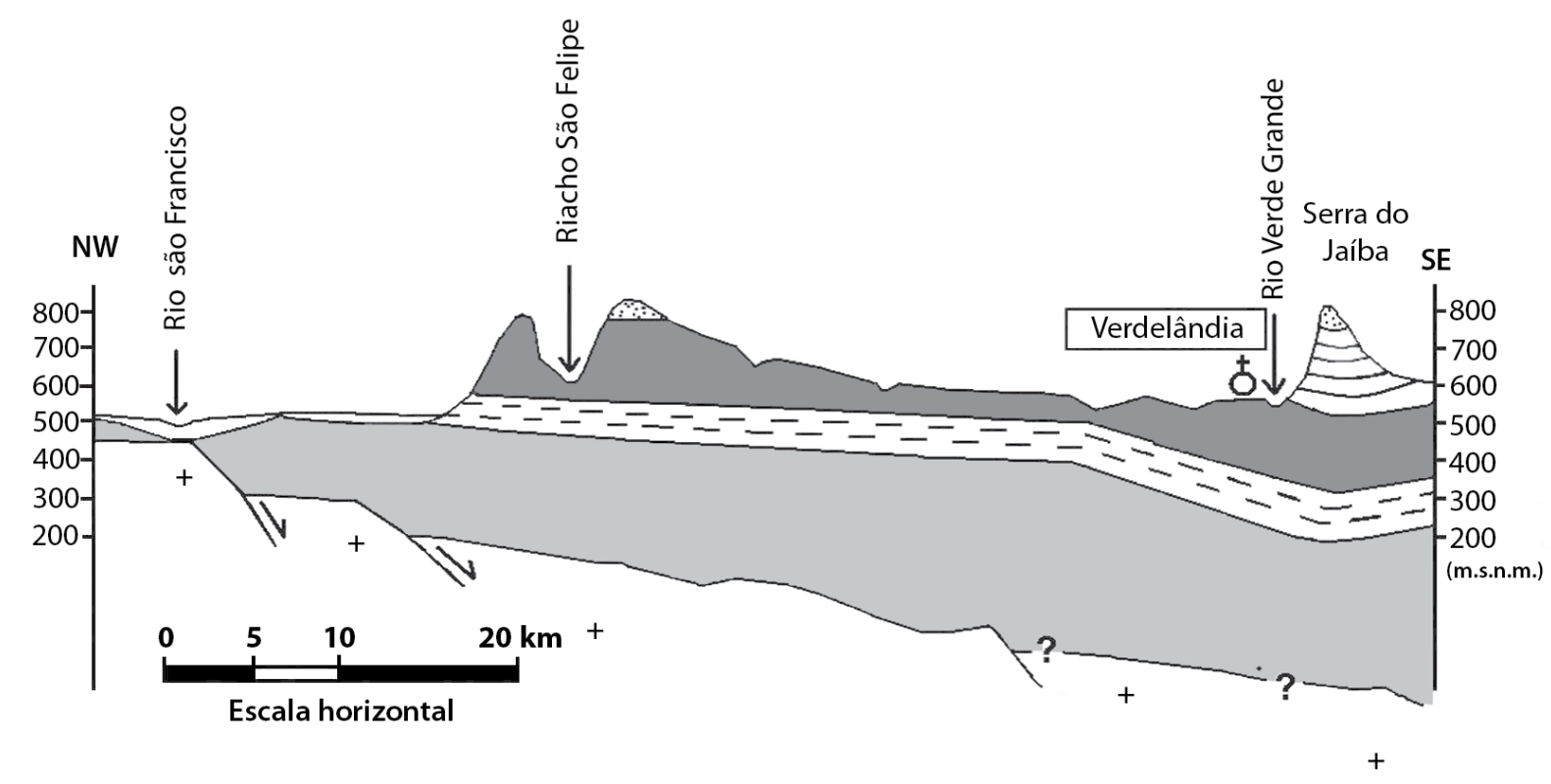

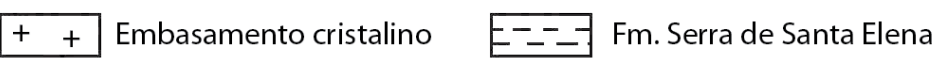
Fm. Serra da Saudade

\section{LEGENDA}

Fm. Sete Lagoas

$\square$ Fm. Lagoa do Jacaré

$\because \because \because \because$ Fm. Três Marias

Coberturas aluviais

む Cidade

Figura 7- Seção esquemática NW-SE, entre a calha do Rio São Francisco e a Serra do Jaíba, mostrando a estrutura sinclinal da Serra do Jaiba. (Segundo Iglesias, 2007 e Iglesias \& Uhlein, 2007).
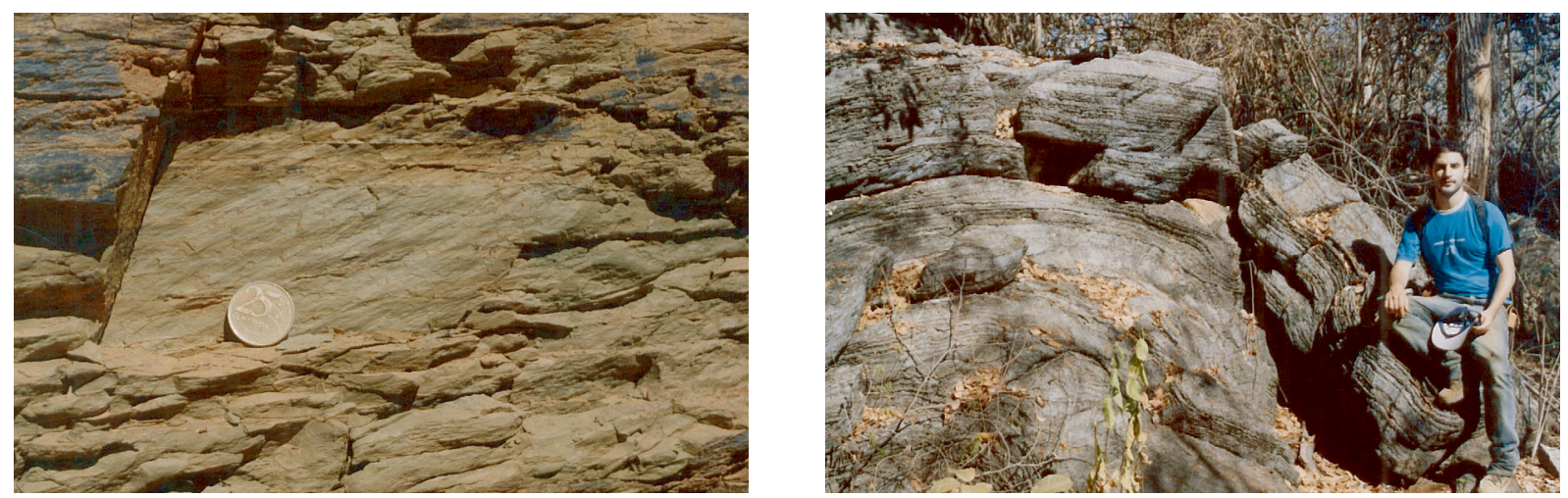

Figura 8.- A) Xistosidade incipiente nos pelitos da Formação Serra da Saudade. B) Aspecto dos dobramentos nos calcários laminados.
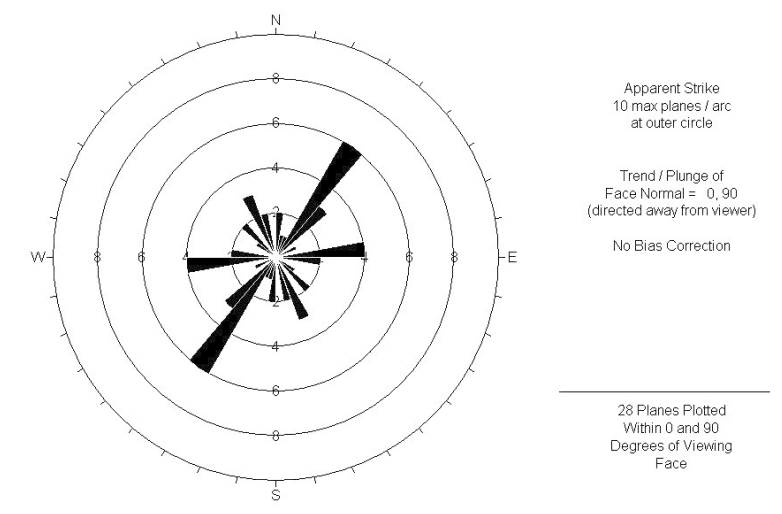

Figura 9- Diagrama de contorno da densidade dos pólos das atitudes de mergulho medidas para as fraturas na área. 


\section{AGRADECIMENTOS}

O presente trabalho inseriu-se nos projetos de pesquisa CNPq CT-Hidro 503.146/2003: Investigação Hidrogeológica do flúor em aqüíferos carbonáticos do Médio São Francisco, MG, e epidemiologia da fluorose dentária associada, coordenado pela profa. Leila Menegasse Velásquez e o projeto FAPEMIG CRA 772/05: Estratigrafia, sedimentologia e recursos minerais do Grupo Bambuí, Minas Gerais, coordenado pelo professor Alexandre Uhlein. Os autores são gratos, também, pelo apoio e ajuda financeira, às seguintes instituições: IGC/UFMG, CAPES, MAE-AECI, CNPq.

\section{REFERÊNCIAS BIBLIOGRÁFICAS}

Chiavegatto, J.R.S., Gomez, N.S., Dardenne, M.A., Delgado, C.E.R. 2003. Estratigrafia do Grupo Bambuí nas regiões do Norte de Minas Gerais: Uma nova unidade estratigráfica em um contexto de inversão de bacia. In: SBG, Simpósio de Geología de Minas Gerais, 12, Ouro Preto, 2003. Anais..., CD rom (1vol)
Costa, P.C.G. 1978. Geología das folhas de Januária, Mata do Jaíba, Japoré e Manga, Minas Gerais. Memória Técnica. CETEC. Belo Horizonte.

Departamento de Estradas e Rodagem-DER. 2004. Mapa Rodoviário do Estado de Minas Gerais.

Iglesias, M. 2007. Estratigrafia e tectônica do Grupo Bambuí no norte do Estado de Minas Gerais. Dissertação de Mestrado, Instituto de Geociências, UFMG. Belo Horizonte. 121 p.

Iglesias, M. \& Uhlein, A. (2007). Estratigrafia do Grupo Bambuí no norte do Estado de Minas Gerais. Submetido à Revista Brasileira de Geociências, no prelo.

RADAMBRASIL. 1982. Folha SD.23 -Brasília, esc. 11000000 , Rio de Janeiro.

Silva, A.B. 1984. Análise morfoestrutural, hidrogeológica e hidroquímica no estudo do aqüífero cárstico do Jaíba, norte de Minas Gerais. Tese de Doutorado. Instituto de GeociênciasUSP. $190 \mathrm{p}$.

Uhlein, A. 1991. Transição craton-faixa dobrada: exemplo do craton do São Francisco e da Faixa Araçuaí (Ciclo Brasiliano) no estado de Minas Gerais. Aspectos estratigráficos e estruturais. Tese de Doutorado, Instituto de Geociências-USP, 295 p.

Uhlein, A., Lima, O.N.B. de, Fantinel, L.M., Baptista, M.C. 2004. Estratigrafia e evolução geológica do Grupo Bambuí, Minas Gerais (Roteiro Geológico). In: SBG, Congr. Bras. Geol., 42, Araxá, Anais..., CD room (1 vol). 